\title{
Metaphysics and learning
}

\author{
Helen Verran
}

Received: 28 December 2006/ Accepted: 10 January 2007/ Published online: 2 March 2007

(C) Springer Science+Business Media, LLC 2007

\begin{abstract}
Is it possible to learn and simultaneously articulate the metaphysical basis of that learning? In my contribution to the forum I tell of how I came to recognise that bilingual Yoruba children could articulate the contrasting metaphysical framings of Yoruba and English numbering. The story introduces an arena I call 'ontics' that recognises the contingencies of metaphysical commitments in the present. My claim is that learning to recognise and strategically articulate ontics as enacted metaphysical commitments in the present is useful in cross-cultural and transdisciplinary learning and crucial in inquiring into learning.
\end{abstract}

Keywords Cross-cultural learning $\cdot$ Metaphysical framings $\cdot$ Ontics · Ontological commitments · Yoruba and Western thought ·

Metaphysics on the run

\section{Introduction}

During the 1970-1980s concerns over relations between culture and thought were all the rage in the Western academy. Amidst the heady aftermath of the popular discovery of culture and difference in the 1960s, along with the American Cold War commitment to winning hearts and minds, for a few years the topic of 'African thought' became a hot topic of academic conversation between philosophers, anthropologists and scholars in other disciplines (Verran, 2001, p. 241, n20). Questions around African children's learning became part of this collective interest as a new discipline 'comparative developmental psychology' emerged (Cole, 1996; Cole \& Scribner, 1974). At that time (and perhaps still) an uncritical Piagetianism held sway amongst those who professed interest in modes of thought and children's learning in cross-cultural situations. The well-attested claim of cognitive deficit amongst 'other' children-African, Aboriginal Australian, Latin American and so 
on, was accepted as an unproblematic truism. This objectively existing problem became the site of much painstaking scientific work (Verran, 2001, p. 11).

I found myself in the midst of this when I took up a position teaching science and science education to teachers in Nigeria in 1979. I have described the surprises that were in store for me in some detail in the first chapter of my book Science and an African Logic (Verran, 2001). My experiences with Nigerian teachers and the children they taught in their classrooms led me to worry about the dismissal of Yoruba forms of knowing implied in developmental psychology (Berry \& Dasen, 1974; Bruner, Oliver, \& Greenfield, 1966) and more generally in discussion of relations between education and development (Gay \& Cole, 1967; Hallpike, 1979; Lloyd \& Gay, 1981).

In particular, taking the failure of African children to work numbers in what were regarded as universally valid ways as an objectively existing social problem and in prescribing solutions based on an understanding that its cause was located in 'primitive thought', the inevitable outcome, good intentions notwithstanding, was systematic de-legitimation of local forms of knowledge which are 'other' to scientifically produced knowledge. Science understood in conventional universalist ways has no basis for recognising as legitimate Yoruba, Wolof or Kpelle knowing and accounts of knowing.

In Nigeria in the 1980s I found myself disconcerted over quite unexpected and inexplicable successes and failures as I worked with my students and their pupils, and angry at the blindness of the Western academy. In response I began developing a theory of many generalising logics. As part of this, with the help of some of my students I carried out a quite large-scale experiment in developmental psychology. The study was designed to show that the logic which Yoruba children learned as members of the Yoruba knowledge community and expressed in Yoruba language and number use, although distinct from, was nevertheless equivalent to, the logic children learned in a scientifically oriented schooling and expressed in English language.

\section{Stumbling across bilingual Yoruba children's facility in re-rendering metaphysical commitments}

The research involved conversations with around 250 children. Using cups of water, and coca-cola, beam balances and peanuts the children I interviewed showed me with gestures and words whether they could generalise about changes in the appearances of matter in valid ways; whether or not they had developed 'habits of looking' at the ways matter presents that would support the generalising implicit in number use. For example I questioned and watched children as they commented on whether and how amount of water was changed when the contents of one of a pair of glasses that the children had agreed contained the same amount was poured from into two separate containers.

Around half of these children were Yoruba speaking children living in Nigeria, the other half were English speaking Australian children I interviewed during a family holiday back home in Victoria, Australia. It is what some of the Yoruba speaking children told and showed me during those conversations I focus on here.

The hundred or so Yoruba children I spoke to fell into two groups: monolingual Yoruba speaking village children, and bilingual children who attended the campus 
school of the university where I lectured. Not surprisingly, the privileged bilingual children belonging to an emerging Yoruba middle class, were far ahead of their village compatriots in terms of their cognitive development concerning quantitative generalising. This was demonstrated irrespective of whether the bilingual children were speaking Yoruba or English. The group of bilingual children I spoke to in Yoruba were also ahead of their English-speaking age cohort in Australia. In development of their capacities in quantitative generalisation bilingual children speaking Yoruba were the most advanced.

This complicated study had showed what others before me had noted, that profound bilingualism often brings cognitive enhancement. But what had not been previously noted or commented on by comparative developmental psychologists were two rather surprising revelations that also emerged from the study. First, the logical basis of generalising about amount of matter in Yoruba is profoundly different than in English. Matter is construed in quite different ways when one is speaking Yoruba than when one is speaking English. The types of entities these groups take for granted as being in the world in their talk of it, differ. I had stumbled across difference in the metaphysical commitments or 'ontics' Yoruba speakers and English speakers routinely operate within. Second, at least some of the children commented on this, finding words to articulate what could be called the metaphysical framing of their generalising.

'Ontics' is a term that will baffle almost all of my readers, pointing as it does to an unfamiliar territory. However I ask for readers' patience. I hope you will make do, and put up with the disconcertment of an incomprehensible term; one that does not mesh with familiar analytic categories. In this section I try to show the notion of ontics before introducing it formally in my next section. I recognise that the next few paragraphs are not easy reading, but I hope that what I mean by 'ontics' will become a little clearer in what follows.

As an initial explanation I ask you to remember the ways counting and measuring are done with repetitions of small bodily gestures involving matter arrayed in particular ways. These gestures include ways of looking at matter, as well as the uttering of particular words-like number names, at particular points in the routine. Ontics-metaphysical commitments to there being certain sorts of things in the world, are both conjured up and expressed in such repetitious bodily gestures and acts of speaking.

Let me also remind you of something else you must already know about using numbers. In English the logic of generalising begins with spatio-temporal particulars that are taken either as separate 'things' like oranges, or like Kilograms or spoonfuls of sugar, as a continuum. Quantifying sugar we often recognise it as having the attribute of mass and we use Kilograms; sometimes we take it as having the attribute of volume and we use spoonfuls. From there generalising proceeds by constituting in acts and words accepted units by which those qualities like thingness, or mass, or volume might be managed. Use of number names when you carry out certain small bodily acts effects quantification. You are using a particular generalising logic, engaging particular ontics, and expressing specific metaphysical commitments.

Ontics embedded in the ways Yoruba speakers do quantitative generalising is profoundly different to that inside number use in English. In Yoruba the logic of generalising begins by noting what sort of matter we are dealing with. It starts with sortal particulars: 'water-matter', 'peanut-matter' and the like. The process of generalising then proceeds to articulation of a unit appropriate for that sort of matter 
here-and-now as a basis for quantification. On this basis number names are introduced and value established.

For many people recognising that a profound difference exists at the level of the logical basis of generalising is a struggle. One of the reasons it is so difficult to make sense of the previous two paragraphs is that we are so used to the story that there is a single universal ontic domain-the one Kant described some 200 years ago. That of course is an ontics that goes along with what were originally Western ways of quantifying, and are now enshrined as scientific ways of using numbers.

The suggestion that many children who are bilingual in radically different languages must appropriate and deal with different ontics in their learning is at first quite shocking. But as we do gradually learn to recognise ontics as a performative domain, we become aware that children who are bilingual in radically different languages must indeed learn to work with, and learn to manage the interruptions and non-coherences. Two profoundly different conceptual schemas must become familiars for those learning the bodily routines of quantify in Yoruba and in English. This learning to deal with cognitive interruption and dissonance is probably the basis of the cognitive enhancement that for some children comes along with profound radical bilingualism.

In introducing my study of 20 years ago I said that two surprising things emerged from listening to what bilingual Yoruba children told me about quantifying. The existence of profound difference in the ontics was the first surprise. The second surprising thing that emerged from my study was that I found around $15 \%$ of these bilingual children were very keen to explain the sorts of connections they were making in managing this ontic interference. They clearly found it interesting and challenging and seemed to enjoy talking of it.

Here is Folake, aged nine. She is commenting on doing a form of practical or empirical ontology-studying ontics. The mutual interruption, the non-coherence of the conceptually disparate logics of generalising in English and Yoruba that she works with has challenged Folake and she has come up with an insightful comparative description that links while still allowing possibilities for distinction. She is explaining in Yoruba why the coca-cola in a bottle is the same as that contained in a plastic mug filled with the contents of a second bottle of coke. "Ara kan náà ní wôn tórí pé inú igò kékéré náà ni won fi si, o si jê kí o jô èyǐ sùgbôn àpapö èyì àti èyì jê ökan náă." (They are the same because they put this there in this little bottle and that made them look like this. But the aggregate of this one [indicating the difference in width of the two containers] and this one [indicating the difference in the two heights of the liquid] is the same one.) Folake is properly engaging Yoruba generalising in talking of a one (kan) but is prepared to comment on the nature of the unitary feature that contingently here and now can form a basis of quantification, a comment that illustrates her familiarity with volume and the possibility of using it as a principle of conservation. She indicates that the stuff is a unit of 'spacefillingness', but she still talks of it as a 'mode of one' (kan). In indicating that the 'mode of one' (kan) that the implied 'coca-cola matter' appears in is 'spacefilling', Folake is connecting across language domains, setting images involved in working English ontics alongside Yoruba ontics.

Recognising and being open and explicit about the possibility and nature of interrupting and connecting at a level of cognition that very few people are aware of, we are working at the level of entities' existence or being-ontics. It is about learning to manage knowing along with doubt; weaning oneself from certainty that is 
allowed by working within just one metaphysical frame. It implies recognising that reality can be done in this way or that, through this series of gestures, words, and material arrangements, or an alternative set.

I have told a story about Yoruba speaking Nigerian children's learning to use numbers embedding profoundly different generalising logics and managing the dissonance that accompanies that. We can understand it as a form of minding metaphysical limits, and learning how to go beyond those limits. What I want to foreground here is the explicit setting side-by-side of non-cohering categories of generalising that many bilingual Yoruba children learn to do, and of which some would readily talk. I want to bring into focus questions of how we can make such insights routine, how we can bring them to the surface and manage them explicitly in learning, particularly in cross-cultural situations. The approach embeds the general notion that recognising and respecting the ontics implicit in local collective action is important. Such recognition implies devising ways of rendering explicit the making of ontic connections (and separations).

\section{'Ontics'?}

I have described stumbling across children explicitly making connections where previously I had not imagined separations as existing. About 20 years ago I found the idea that such links (and separations) could be made, and made in better and worse ways was both startling and difficult to articulate. Previously I had gone along accepting the Kantian compromise and assumed the existence of a singular given noumena-necessary things that are thought. Or rather I went along with one particular version of what Kant's compromise had become near the end of the 20th century. In this section I make a diversion to explain the nature of this compromise, where the term 'ontics' comes from, and why I use this unfamiliar term that interrupts, and perhaps 'puts off' my readers.

Kant (1724-1804) credited David Hume (1711-1776) with bringing him to his senses. Hume's analysis of the notion of cause and effect cut the ground from the idealist (Leibnizian) metaphysics Kant had previously accepted. A philosopher at the centre of the Scottish Enlightenment, Hume was at pains to show the limitations of a notion of reason based on ideals, and explained how we make the judgements we do on the basis of the human experience of being in the world. In taking up Hume's challenge Kant agreed that his critique left no alternative but to look to the senses. But Kant went beyond Hume and invested his empiricism with a new form of metaphysics, in claiming that senses represent not only the empirical 'out-there' but also the mind 'in-here'. This makes it possible for the mind itself to generate a priori concepts.

Kant's solution to Hume's puzzle is offered as a radically transformed metaphysics - a critical metaphysics, to use Kant's term. According to Kant the world's most general features - such as its empty spacetime framing of matter, and causation understood within this spacetime/matter frame, are imposed on it by 'us' as absolutes. Consequently those features which we can know a priori and are the contents of a respectable metaphysics belong merely to the world as we experience it and not to the world as it really is in itself independently of human cognition. Thus the 'thing in itself,' the noumena, is known by not being knowable. By definition it transcends all experience. 
Some philosophers call this realm of the noumena, 'the ontic'. Most philosophers understand 'the ontic' as complete, static and with given distinct separations. Yet being tricky and paradoxical (being known by being unknowable) it is difficult to characterise. Some like Kant, Husserl and Heidegger understand it as depending in large measure on what humans contribute. Heidegger differs from Kant and Husserl in that his 'we' who know 'the ontic', are concrete existing beings as distinct from (a Kantian) pure consciousness seeing from nowhere and everywhere. Some 20th century philosophers reject Kant's compromise for dealing with the paradox in which the ontic is embedded. For Quine an American logical positivist philosopher, the ontic, existing on the other side of a stimulus gap is ineffable and inscrutable, merely its existence is attested by the senses. As Quine sees things the best we can do is struggle to be clear about the ontic commitments entailed in knowing.

Conventionally ontology is the term given to study of 'the ontic'. Not surprisingly relations between 'the ontic' and its study 'ontology', is cause for much discussion. Husserl and Heidegger try to describe the ontic without the help of theories and preconceptions, which Heidegger maintains can only be achieved by totally re-thinking the language of philosophy. For Quine in contrast ontology can merely be asking about the validity of ontic commitments.

Doing ontics as I understand it could hardly be more different from the ways these 20th century philosophers imagined it. Mine is not a quest to describe how things are. For me ontics recognises itself as emergent, partial and performative, where actual entities function like actor-networks (Akrich, Callon, \& Latour, 2006; Law, 2004). This notion of ontics is inspired by (among others) the early 20th century British philosopher A.N. Whitehead, and Australian John Anderson (although unlike their image, it refuses the givenness of reality configured as matter set in spacetime while recognising that configuration as achieved realness) and the contemporary French philosopher Michel Serres.

Ontics as I use it does not aspire to completeness and accepts and values vagueness. Ontics is a politics of rendering our metaphysical commitments visible, often by telling stories, but also in other sorts of embodied performance. Doing ontics is doing a politics that is continually straining towards doing another sort of politics-ontological politics where we discuss if and how we might make explicit our metaphysical commitments and so interrupt and create possibilities for considering re-rendering our worlds; articulating alternative metaphysical commitments and doing things differently. Ontics depends to some extent on what we humans contribute in our embodied participation with the non-human in collective acting (including doing ontics). Ontics recognises that ontic commitments (re)emerge in often unacknowledged and unrecognised collective action which accompanied by considerable inertia, but which nevertheless are not given once and for all.

Let me briefly illustrate this possibility of change in ontics by telling a story of space. This story will help in beginning to see an ontic politics inherent in Kant's critical metaphysics. Empty, universal and absolute space and time are a significant element in 'the ontic' of many 20th century philosophers, just as it is central to Kant's noumena. When we have ontics as enacted, space, including the empty, universal, and absolute space of modernity, is recognised as an outcome of collective acting. Going further, we recognise that space emerges and exists as multiple entities, which connect in various ways, but sometimes might also interrupt and clash.

The space Kant assumed was the outcome of collective activities of doing space in the late 18th century when he was writing-sailing off into the unknown with only 
sextant and compass and their associated cartographic traditions to render the bits of the continents you came across, re-locatable in a world imagined as a grid.

Many geographers now insist on recognising a new 21st century way of doing space. Thrift (2004) suggests that in many places today space is now predominantly practices of doing positionality. This new sort of space is the outcome of working in alternative ways with different materialities, different institutions, differing ways of textualising, and (re)imagining collective action. In involves alternative sets of bodily movements and other sets of words and linguistic conventions. In the emergence of space as positionality as reality of the 21 st century, the carefully arranged materialities of today's information communication technologies are important, but only one element. The increasing predominance of tracked and self-tracking position as space, can sometimes be connected up ontically with space as empty extension (as Kant imagined it) but not always, or often.

In this new way of understanding the multiple realities of space we also come to recognise that many sorts of space were likewise being 'done' in the 18th century. In accounting what he saw as an absolute space Kant attended to a particular set of collective activities - those valued by the emerging imperialist states of Europe. But at the same time as that sort of space was being done by agents of the state (for example, the grand British trigonometrical survey of India), other sorts of space were being done by agents involved in different projects. For example officers of the East India Company did space by plying a route. They used familiar landmarks in developing complicated route maps (Barrow, 2002). Recognising the multiplicity which follows from having ontics as enacted brings with it the need for a new understanding of metaphysics and possibilities associated with a canny use of metaphysics. We need to go beyond Kant's singular world.

\section{Ontics as enacted}

In trying to understand and explain what a group of Nigerian children had shown me, I found that a new imaginary, a new account of realness, including how it is known, and the process of becoming a knower-learning, was needed to understand the workings of multiple generalising logics. I needed a notion of knowledge and learning that had realness as emergent in collective action. I saw that if I was to do analysis that recognised as real the difference that Yoruba and English speaking children had revealed to me, I had to abandon my old working image of realness, of knowledge, and learning that had the world as singular and 'out-there' and knowledge as habits of certain thought.

I had to jettison an account of realness which up to that point I had never doubted, indeed had never imagined could be doubted. The Yoruba and English speaking children I listened to had shown and in some cases eloquently explained difference in generalising logics. But the image of there being a single given foundation for knowledge to be about, an image central to many Western theories of knowledge (epistemologies), was getting in the way of my being able to work with this difference as real, as part of collective life in the here and now.

The new working imaginary that I came to espouse conjures up multiple enacted realities. The singularity of the sciences' reality is seen as a special sub-set of the prevailing multiplicity effected in collective action. Entities-both objects and subjects, materialise or 'clot' as configured in particular ways in the here-and-now. This 
can be understood as a partial account of the ontic commitments of those working in an arena that is often vaguely standardised (in the sense of gathering behind a standard bearer) as actor-network theory.

In this new imaginary, realness is achieved in the emergence of webs of gradually clotting, and eventually routinised sets of actions that connect as nodes. These nodes are established sets of embodied acts and mostly banal, but sometimes innovatory. Acts performed and re-performed in a repetitious, ritual-like way. The repetitions pre-script times-places to both promote and limit creativity. In some cases like numbers, we are so familiar with these routines that they are often invisible.

The image of a web here is not one that is spun or regular in any way. It is more like the web of that would emerge were a piece of felt to be pulled out to a flopping filmy gossamer, folding and wrinkling where irregular connections and breakages between the wool fibres emerge. Another image sees one of the new sorts of colloid materials marketed to children as 'play goo' stretched to a film. The irregular nodes amongst the strands that form are the relationalities within which entities emerge.

Numbers in this ontic sense are like all entities in inhabiting the spaces or intervals between collective enactments. Numbers seem to lie there mostly just out of focus in collective life, always ready to actively re-exist when we do the right actions and say the right words. I imagine numbers pulsating and quivering there in these intervals, always in potentia, apart from their brilliant, ephemeral realisation or clotting in enactment, time and time again. But it is not only numbers that exist in this oscillating way, forever ready, awaiting their cue in the wings. All entities lie suspended between enactments of their possibilities. Entities lurk or loom in the interstices between the repetitions by which they are done. The relationalities through which they exist are external to their being 'clotted' entities. That is how all entities express relationalities; how entities (actors or actants) are networks; and how networks of relations are entities.

\section{How to tell learning and enquiring into learning as 'doing' multiple emergent realities?}

In concluding I return to the children who first alerted me to the possibility of becoming familiar with metaphysical commitments and consider what might follow from such familiarity. These children had me doing the arduous work of articulating a new account of generalising, arising from an alternative notion of realness as achieved in on-going collective action.

This new account of generalising refuses notions of abstraction and foundations as salient to accounting knowledge and knowers in the here-and-now. Instead it has knowers/learners treating what functions as metaphysical framings and what is framed as one and the same in the ontics of the here-and-now; the ontological flatlands of the present.

In this alternative account of realness and generalising, knowers - in my experiment children learning to generalise about matter, and an experimenter generalising about generalising, and what is known - the generalisations, emerge all of a piece. These generalisations are qualities that peanuts and coca-cola have if we go along with the metaphysical commitments of Western quantification, or modes of presenting as units if we go along with the ontics of Yoruba thought, or generalisations 
about generalisations if we switch our gaze from the children to the woman they are talking to.

Generalisers and generalisations emerge from learning to constitute working framings, but what these sharp Yoruba bilingual children showed me was that it is just as important to be able to dissolve and promiscuously (re)constitute new sorts of framings and to know that and how you are doing this. These children showed me that we can choose to frame the puzzle of the ways the contents of a bottle of cocacola look different when poured into a wide squat plastic mug with notions of spacefilling-volume, as Western thought explains away this banal puzzle. Or we can frame using the notion of mode of one-ness as Yoruba thought explains away the incompatible perceptions, making difference as sameness; or we can do both simultaneously. Following their lead and promiscuously re-rendering the metaphysical framings of my experiment to come up with two contradictory explanations of the results of one experiment, and insist on the truth of the contradiction (Priest, 2002), I learned to investigate learning in a way that would allow me to remain in the actual here-and-now openly negotiating my metaphysical commitments with the humans and non-humans I was committed to going on with. Inquirers into learning are learners in the here-and-now and the generalisations they come up with are simultaneously singular and multiple, open to re-renderings. In cross-cultural situations at least this necessarily involves learning to do metaphysics on the run.

\section{References}

Akrich, M., Callon, M., \& Latour, B. (2006). Sociologie de la traduction: Textes fondateurs. Paris: Presses de l'Ecole des Mines de Paris.

Barrow, I. (2002). Making History, Drawing Territory British Mapping in India, c. 1756-1905. Oxford: Oxford University Press.

Berry, J., \& Dasen, P. (Eds.). (1974). Culture and cognition: Readings in cross-cultural psychology. London: Methuen.

Bruner, J, Oliver, R., \& Greenfield, P. (Eds.). (1966). Studies in cognitive growth. New York: Wiley.

Cole, M. (1996). Cultural psychology: A once and future discipline. Cambridge MA: Harvard University Press.

Cole, M., \& Scribner, S. (1974). Culture and thought a psychological introduction. New York: Wiley.

Gay J., \& Cole, M. (1967). The new mathematics in an old culture: A study of learning among the Kpelle of Liberia. New York: Holt, Rinehart and Winston.

Hallpike, C. (1979). The foundations of primitive thought. Oxford: Clarendon Press.

Law, J. (2004). After method: Mess in social science research. London: Routledge.

Lloyd, B., \& Gay, J. (Eds.). (1981). Universals of human thought: Some African evidence. Cambridge: Cambridge University Press.

Priest, G. (2002). Beyond the limits of thought. Oxford: Clarendon Press.

Thrift, N. (2004). Remembering the technological unconscious by foregrounding knowledges of position. Environment and Planning D: Society and Space, 22, 175-190.

Verran, H (2001). Science and an African Logic. Chicago: University of Chicago Press. 